\title{
Recolha, preservação e contextualização de objectos digitais para dispositivos móveis com Android
}

\author{
Raquel Soares ${ }^{1}$, Marco Pereira ${ }^{1}$, Joaquim Arnaldo Martins ${ }^{1}$ \\ raquel.soares@ua.pt, marcopereira@ua.pt,jam@ua.pt \\ ${ }^{1}$ DETI - Departamento de Electrónica, Telecomunicações e Informática, \\ IEETA - Instituto de Engenharia Electrónica e Telemática de Aveiro, \\ Universidade de Aveiro, Campus Universitário de Santiago, 3810-193 Aveiro, Portugal.
}

DOI: $10.4304 /$ risti.9.75-89

\begin{abstract}
Resumo
Motivação: Com a crescente expansão e utilização de dispositivos móveis, emergiu rapidamente a necessidade de recolha e preservação de objectos digitais. Cada vez mais, é importante tornar a nossa informação persistente e acessível em qualquer momento e em qualquer lugar. E se, para além do acesso, existisse a possibilidade de contextualizar cada objecto digital? Desta forma, o utilizador poderia relembrar a origem e fundamento dos respectivos dados ao longo de toda a sua vida.

Resultados: A aplicação CoBy surge com o intuito de permitir ao utilizador recolher, preservar e contextualizar todos os objectos digitais que vão surgindo no seu dispositivo móvel com sistema operativo Android. A cada um deles vai sendo associada a respectiva geo-localização de onde ocorreram. Estão disponíveis também funcionalidades de backup e restore a partir do próprio dispositivo móvel ou da Cloud. Esta aplicação dará um forte contributo no que toca à preservação e contextualização do património digital pessoal.
\end{abstract}

Palavras-chave: Objecto digital; Contexto; Preservação digital; Geo-localização; Dispositivo móvel.

\begin{abstract}
Motivation: The increasing use and growth of mobile devices, spurred the need to collect and preserve digital objects. More and more, it is important ensure that our information becomes persistent and accessible anytime and anywhere. What if, besides access, there was the possibility of contextualize each digital object? If so, the user could recall how, what and why it stored that data, throughout their lives.

Results: The CoBy application was created in order to allow the user collect, preserve and contextualize all digital objects that will appear in mobile devices with Android as operating system. Each of them will be associated with place where they occurred (geo-location). The application includes other features, such as backup and restore from the mobile device or from the Cloud. This application
\end{abstract}


provides a strong contribute to the preservation and contextualization of a person's digital heritage.

Keywords: Digital object; Context; Digital preservation; Geo-location; Mobile device.

\section{Introdução}

A existência de objectos digitais no nosso dia-a-dia tem tido, ao longo dos últimos anos, um enorme crescimento. Estes podem ser concebidos como artefactos compostos tendo em conta três elementos essenciais: conteúdo, metadados e a sua relação com outros objectos (Saidis \& Delis, 2007). Os objectos digitais podem assumir os mais variados tipos, retratando grande parte da nossa vida pessoal e profissional, e representam toda informação digital presente em dispositivos electrónicos como: computadores, telemóveis, smartphones, tablets, entre outros. Esta informação digital é extremamente importante, para as pessoas que utilizam estes dispositivos, e ao mesmo tempo muito delicada e frágil. Se não tomarmos as devidas precauções, a qualquer momento pode-se perdê-la, e em alguns casos nada se pode fazer para contrariar a situação. É extremamente importante permitir aos detentores (utilizadores) de objectos digitais formas de os preservar. Assim, o utilizador consegue não só manter todas as suas memórias de sempre e para sempre, mas também dar o seu contributo para a passagem de conhecimento de geração em geração. É humanamente impossível recordar todos os acontecimentos que vão emergindo ao logo da vida, e como "Sem memórias não há história"(da Costa, 2007), é crucial investir afincadamente nesta área. Com a sociedade maioritariamente digital em que vivemos hoje em dia, e a avançar a passos largos para se tornar inteiramente digital, é gritante a necessidade de preservar todo o material digital que dispomos, caso contrário, torna-se um pedaço da nossa história pessoal e universal que se perde.

Da necessidade de evitar a perda de informação digital surgiram os repositórios digitais (Heery \& Anderson, 2005). Neles é possível armazenar colecções de objectos digitais, e que podem ser acedidos e recuperados para utilização imediata ou posterior. Um repositório digital suporta mecanismos de importação, exportação, identificação e armazenamento de objectos digitais. Para além disso, um repositório digital oferece ao utilizador uma interface permitindo-lhe aceder ao conteúdo que pretende. $\mathrm{O}$ uso de repositórios digitais traz benefícios a todos, até mesmo ao meio ambiente, evitando o consumo de alguns recursos naturais que tendem a escassear. A utilização vigorosa de repositórios digitais poderia contribuir para o atenuar deste problema, diminuindo a necessidade dos utilizadores preservarem os seus dados/conhecimentos em papel.

A necessidade de preservar a informação digital inerente à flexibilidade de armazenamento de qualquer tipo de objecto digital despoletou o aparecimento dos repositórios digitais pessoais. Estes permitem ao utilizador guardar os seus objectos digitais garantindo-lhe alguma capacidade de armazenamento e um controlo de acesso bastante prudente. Um utilizador quando recorre a este tipo de serviço pretende armazenar os seus dados para consulta e utilização a curto e longo prazo. Os repositórios digitais pessoais permitem a preservação controlada e persistente do nosso material digital, possibilitando o seu acesso em qualquer momento e em qualquer 
lugar, por quem de direito. A segurança dos dados é inteiramente assegurada, dado que só terão acesso as pessoas que o utilizador permitir e os conteúdos que este definir.

Tendo a preservação dos nossos objectos digitais assegurada, levanta-se a questão: Será que conseguimos lembrar o seu contexto? O contexto, também designado como Context Awereness na literatura (Mehra, 2012), (Abowd, Ebling, Hung, Lei, \& Gellersen, 2002), (Dey, 2001), (Pascoe, 1998), pode ser visto como uma análise ao contexto pessoal, social, histórico, físico, ambiental, posicional, etc., de um objecto digital. Resumidamente, o contexto de um objecto digital é tudo aquilo que fomenta o seu surgimento, a forma como é usado e interpretado, a que propósito foi concebido, o que influenciou a sua criação, local do evento, a sua relação com os outros objectos, entre outros. Segundo Arellano (Arellano, 2004) uma aplicação cuja finalidade recai sobre a preservação de informação deve ter sempre presente o seu conteúdo, estrutura e contexto. É muito útil termos os nossos dados preservados, mas também é indispensável saber o seu contexto, para ao longo dos anos ser possível fazer a reconstrução da imagem mental do objecto digital.

Tal como é ilustrado na Figura 10, este projecto tem como principal objectivo recolher alguns objectos digitais e guardá-los num repositório digital pessoal presente na Cloud. Esta recolha é efectuada num dispositivo móvel com sistema operativo Android. Sempre que possível, é adicionada alguma informação que permita contextualizar cada objecto digital. É possível colocar no repositório os mais variados tipos de informação, como por exemplo: SMSs, contactos, histórico de chamadas, bookmarks, imagens, emails, páginas Web visitadas, lista de compromissos, entre muitos outros. Todo o material digital é preservado e sempre que o utilizador pretender tem total acesso a ele, independentemente do sítio, do tempo, do sistema operativo e do dispositivo de acesso. Existe ainda a liberdade de poder partilhar os seus conteúdos digitais com amigos, usando para isso as redes sociais (Facebook, YouTube, Flickr, Linkedin, entre outros), ou simplesmente permitir o acesso de determinada pessoa ao seu repositório digital pessoal.

Este projecto engloba diversas áreas de desenvolvimento, exigindo a integração de tecnologias bastante distintas. No entanto, a área móvel merece especial atenção, devido ao seu elevado crescimento e actual impacto na sociedade. Desta forma, este trabalho é desenvolvido a pensar nas pessoas e nos seus interesses, sendo que os dispositivos móveis contêm uma grande quantidade de informações pessoais altamente sensíveis. Então, neste contexto, deve-se desenvolver uma aplicação que tenha em conta esta delicadeza e ajude a preservar os conteúdos presentes nos dispositivos móveis. A aplicação CoBy (Contextualized Backup and Restore) foi desenvolvida para recolher alguns dos objectos digitais presentes em dispositivos móveis Android (smartphone ou tablet), contextualizá-los, e enviá-los para o repositório digital pessoal, tal como é exposto na Figura 11. Neste caso específico, e numa abordagem inicial, para além do contexto a que um objecto digital está sujeito, adicionou-se o contexto de geolocalização. A informação digital é guardada numa base de dados local (backup) no cartão de memória do dispositivo móvel e/ou enviada para o repositório, já devidamente contextualizada. Também é dada a possibilidade de restaurar (restore) os dados do repositório ou do cartão de memória de volta para o dispositivo móvel (Ottaviani, Lentini, Grillo, Di Cesare, \& Italiano, 2011). Esta funcionalidade é extremamente importante caso haja uma mudança ou furto do smartphone ou tablet. 
Desta forma, o utilizador pode voltar a ter todo o seu conteúdo digital de volta no dispositivo móvel. O repositório digital pessoal disponibiliza ainda, ao utilizador uma interface (página $W e b$ ) para visualização do seu conteúdo. Este pode ser visto sobre a forma de timeline temporal, tendo capacidade de filtragem de informação usando alguns parâmetros, como por exemplo a geo-localização.

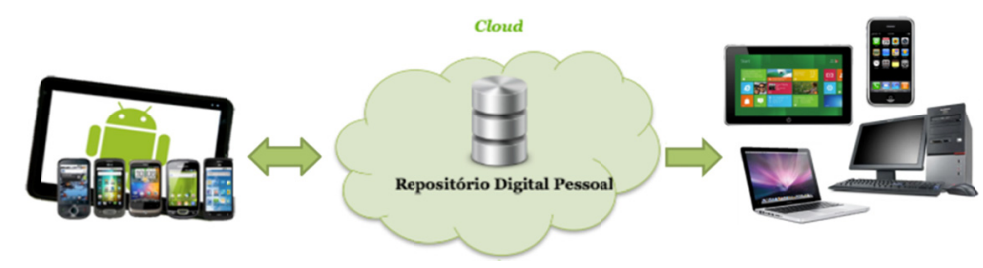

Figura 10 - Visualização e recolha de informação digital do utilizador.

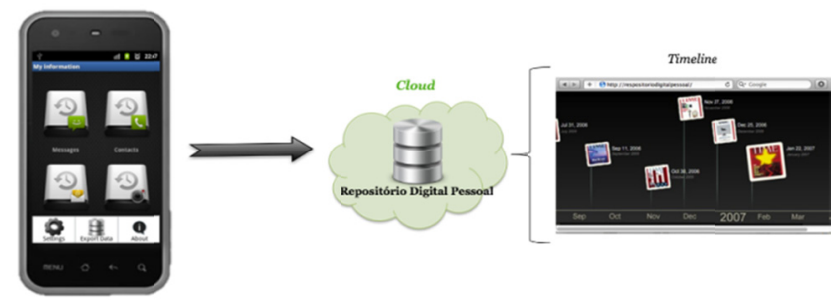

Figura 11 - Esquema ilustrativo da área móvel do projecto.

Desenvolveu-se a aplicação direccionada para dispositivos móveis com Android. Esta escolha deveu-se ao facto deste sistema operativo estar neste momento com a maior cota de mercado mundial (Gartner, 2012). E prevê-se que esse crescimento se acentue ainda mais (Darwin, 2012).

\section{Trabalho relacionado}

Ao longo da história o homem foi desenvolvendo formas de preservar a sua informação, recorrendo a pinturas, fotografias, manuscritos, livros, entre muitas outras coisas. Mas, devido à evolução da tecnologia, foi surgindo outro tipo de informação, que contribuiu para a sociedade da informação em que se vive actualmente, amplamente rodeada de conhecimento digital. Foi igualmente necessário o desenvolvimento de ferramentas de salvaguarda deste tipo de dados. $\mathrm{Na}$ área móvell esta preocupação torna-se acrescida devido à elevada vulnerabilidade dos seus objectos digitais. A pensar nesta questão, inúmeras aplicações foram desenvolvidas.

O sistema operativo Android disponibiliza uma aplicação designada Play Store, onde é possível obter todas as aplicações disponíveis no Google Play, a loja de aplicações do Android. Foi efectuada uma pesquisa usando a Play Store de um dispositivo móvel em busca de aplicações que permitissem efectuar backup e restore de dados. O resultado dessa pesquisa está ilustrada na Tabela 1 onde se encontram representadas as mais usadas. À semelhança da aplicação CoBy, todas elas disponibilizam funcionalidades de 
backup e restore dos dados, à excepção da aplicação Backup Contacts que apenas permite fazer backup. A ausência da funcionalidade de restore torna esta aplicação limitada.

A capacidade de fazer backups automáticos é uma funcionalidade muito útil para este tipo de aplicações. Liberta o utilizador da necessidade de o realizar manualmente, que poderia conduzir a alguma perda de informação, caso o utilizador não se recordasse de o fazer com alguma regularidade. Esta funcionalidade está presente na aplicação CoBy, contrariamente ao que acontece por exemplo nas aplicações Backup Contacts, Mobile Backup II e Super Backup. Trata-se de uma funcionalidade que transmite uma maior confiança e segurança ao utilizador.

Analisando as aplicações retratadas na Tabela 1, observa-se a existência de duas abordagens distintas no que toca aos dados alvo. Existem aplicações que centram as suas atenções apenas num tipo específico de dados, como é o caso da SMS Backup \& Restore, Call Logs Backup \& Restore, Backup Contacts, etc. Assim como existem outras, que à semelhança da aplicação CoBy, são bastante mais abrangentes permitindo simultaneamente o backup e restore de objectos digitais distintos. Um bom exemplo disso são as aplicações: SMS Backup +, JS Backup, Mobile Backup II e Backup Master, etc. A capacidade de fazer backup e restore de vários objectos digitais, numa só aplicação, confere-lhe uma grande versatilidade, evitando a necessidade do utilizador instalar uma aplicação por cada tipo de dados.

Tabela 1 - Aplicações presentes no Google Play mais usadas para backup e restore (*Aplicações pagas).

\begin{tabular}{|c|c|c|c|c|c|}
\hline $\begin{array}{l}\text { Aplicaçöes } \\
\text { [Fabricante] }\end{array}$ & Backup & $\begin{array}{c}\text { Backups } \\
\text { automáticos }\end{array}$ & Restore & $\begin{array}{l}\text { Destino dos } \\
\text { dados }\end{array}$ & Dados alvo \\
\hline $\begin{array}{l}\text { App Backup \& Restore } \\
\text { [INFOLIFE LLC] }\end{array}$ & & & & Cartão memória & Aplicações \\
\hline $\begin{array}{l}\text { SMS Backup \& Restore } \\
\text { [RITESH SAHU] }\end{array}$ & & & & $\begin{array}{c}\text { Cartão memória, } \\
\text { E-mail }\end{array}$ & SMS \\
\hline $\begin{array}{l}\text { Titanium Backup root } \\
\text { [Titanium Track] * }\end{array}$ & & & & Cartão memória & $\begin{array}{l}\text { Aplicações, dados associados à } \\
\text { aplicação }\end{array}$ \\
\hline $\begin{array}{l}\text { SMS Backup + } \\
\text { [Jan Berkel] }\end{array}$ & & & & E-mail & SMS, MMS, Histórico chamadas \\
\hline $\begin{array}{l}\text { SMSBackup \& Restore } \\
\text { [INFOLIFE LLC] }\end{array}$ & & & & Cartão memória & SMS \\
\hline $\begin{array}{c}\text { Call logs Backup \& } \\
\text { Restore [Ritesh Sahu] }\end{array}$ & & & & Cartão memória & Histórico chamadas \\
\hline $\begin{array}{c}\text { JSBackup } \\
\text { [Johospace Co.,Ltd.] }\end{array}$ & & & & $\begin{array}{c}\text { Cartão memória, } \\
\text { DropBox, } \\
\text { Sugar Sync, } \\
\text { GoogleDocs }\end{array}$ & $\begin{array}{l}\text { SMS, Contactos, Bookmarks, } \\
\text { Histórico chamadas, Calendário, } \\
\text { Aplicações, etc }\end{array}$ \\
\hline $\begin{array}{l}\text { Backup Contacts } \\
\text { [Red Rock AS] }\end{array}$ & & & & $\begin{array}{l}\text { Cartão memória, } \\
\text { DropBox, E-mail }\end{array}$ & Contactos \\
\hline $\begin{array}{l}\text { Mobile backup II } \\
\text { [MobileHome Corp.] }\end{array}$ & & & & Cartão memória & $\begin{array}{l}\text { SMS, Contactos, Histórico } \\
\text { chamadas, Eventos do calendário }\end{array}$ \\
\hline $\begin{array}{l}\text { Super Backup : SMS \& } \\
\text { Contactos } \\
\text { [Mobile Ideia Studio] }\end{array}$ & & & & Cartão memória & SMS, Contactos, Histórico chamadas \\
\hline $\begin{array}{c}\text { Bookmark Sort \& Backup } \\
\text { [happydroid] }\end{array}$ & & & & Cartão memória & Bookmarks \\
\hline $\begin{array}{l}\text { Backup Master } \\
\text { [Funny Android Games] }\end{array}$ & & & & Cartão memória & $\begin{array}{l}\text { Aplicações, SMS, MMS, Bookmarks, } \\
\text { Histórico chamadas, Alarmes, etc }\end{array}$ \\
\hline $\begin{array}{l}\text { BackupandShare Backup } \\
\text { Solution [Aress Software] }\end{array}$ & & & & $\begin{array}{l}\text { Servidores } \\
\text { próprios }\end{array}$ & $\begin{array}{l}\text { Contactos, Fotografias, Videos, } \\
\text { Músicas, Imagens }\end{array}$ \\
\hline $\begin{array}{l}\text { MyBackup Pro } \\
\text { [Rerware, } L L C] \text { * }\end{array}$ & & & & $\begin{array}{l}\text { Servidores } \\
\text { próprios, Cartão } \\
\text { memória }\end{array}$ & $\begin{array}{l}\text { SMS, MMS, Histórico chamadas, } \\
\text { Contactos, Fotografias, Bookmarks, } \\
\text { Calendário }\end{array}$ \\
\hline $\begin{array}{c}\text { SMS BACKUP } \\
\text { n2manager [n2manager] }\end{array}$ & & & & Cartão memória & SMS \\
\hline
\end{tabular}

Dentro das aplicações estudadas, os dados de backup podem ser armazenados em locais distintos, sendo eles o cartão de memória do dispositivo móvel, um repositório pessoal e/ou uma conta de e-mail. O local de armazenamento de informação mais comum é o cartão de memória. Mas, se perdermos o dipositivo móvel, ou se houver um 
furto do mesmo, o facto de termos um backup dos nossos dados no cartão de memória do dispositivo de nada serve, pois a informação perder-se-á. A salvaguarda de dados num repositório pessoal é indispensável e está presente nas aplicações JS Backup e Backup Contacts. A aplicação CoBy oferece um repositório semelhante, mas com funcionalidades acrescidas. Os ficheiros de backup são colocados no repositório pessoal não só para efectuar o restore posterior, mas também permite ter os dados permanentemente sincronizados. Os dados presentes no dispositivo móvel vão corresponder aos dados que estão armazenados no repositório pessoal. Esta funcionalidade permite que o repositório tenha sempre a versão mais actual do estado do dispositivo móvel. O acesso ao repositório pode ser feito em qualquer altura e em qualquer lugar, por qualquer sistema operativo.

A capacidade de preservar informação é evidente em todas as aplicações da Tabela 1, mas nenhuma delas proporciona ao utilizador a possibilidade de filtrar os dados que pretende conservar. Existem sempre objectos digitais que a sua preservação não é desejada. Esta funcionalidade encontra-se apenas presente na aplicação CoBy.

Contrariamente às restantes, a aplicação CoBy, permite recolher informações extras relativas ao contexto de um objecto. Para além do contexto comum usado (data, hora, destinatário, etc.), esta aplicação permite recolher o contexto geo-espacial do objecto. Trata-se também de uma característica única desta aplicação.

Naturalmente, todas as aplicações tem os seus pontos fracos e fortes. A aplicação CoBy distingue-se positivamente das restantes, sobretudo ao nível da geo-contextualização, filtragem de informação e a preservação da informação num repositório digital pessoal com funcionalidades acrescidas.

\section{Modelo e arquitectura}

Na Figura 12 está representado o modelo que pode ser usado para a criação de aplicações de recolha, preservação e contextualização de objectos digitais, no qual a aplicação Coby representa o seu protótipo. 


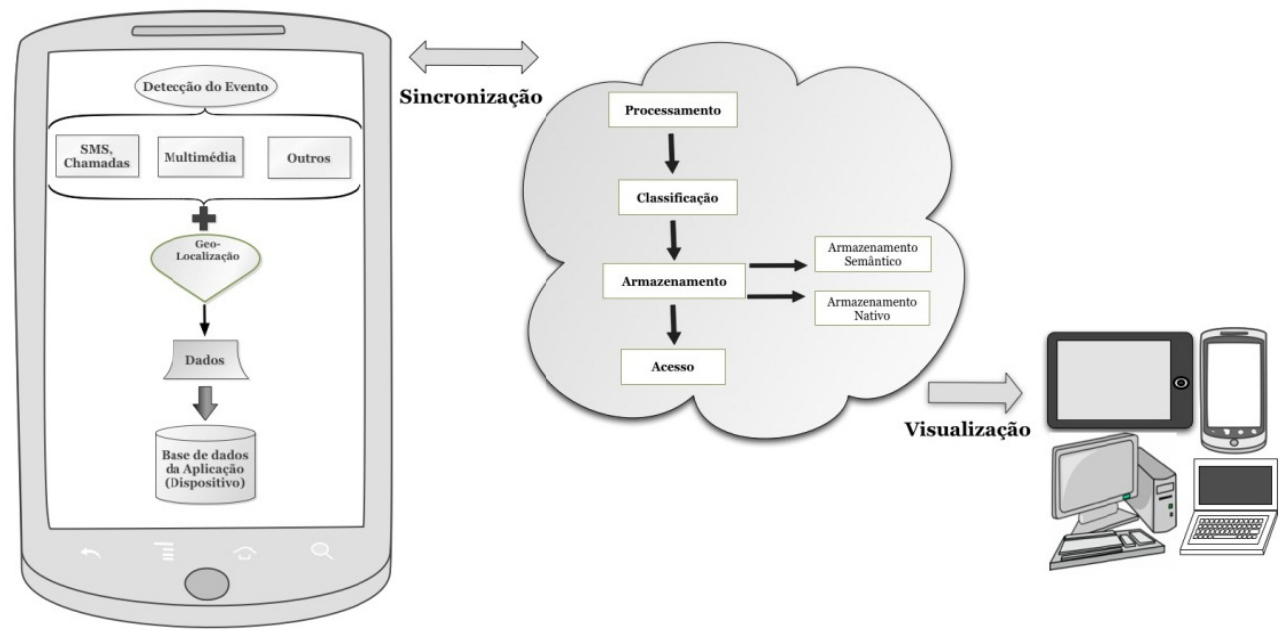

Figura 12 - Modelo genérico de recolha, preservação e contextualização de objectos digitais baseado no modelo OAIS (BOOK, 2002)

A aplicação CoBy tem a capacidade de recolher, preservar e contextualizar, numa fase inicial, objectos digitais do tipo SMSs (Short Message Service), chamadas e contactos. O utilizador tem a possibilidade de fazer backups automáticos para o cartão de memória (SD card, Secure Digital Card) do seu dispositivo móvel ou para o seu repositório digital pessoal presente na Cloud (Figura 13). Sempre que o utilizador pretender restaurar as suas SMSs, histórico de chamadas ou contactos de volta no dispositivo, pode fazê-lo não só a partir do backup existente no seu cartão $S D$, como também do repositório digital pessoal. Para o fazer a partir do repositório só precisa de uma ligação à Internet activa. Os dados enviados para o repositório ou guardados no cartão SD já se encontram devidamente contextualizados. Esta aplicação integra funcionalidades como obtenção da localização do utilizador, persistência de dados no dispositivo e consumo de Web-services.

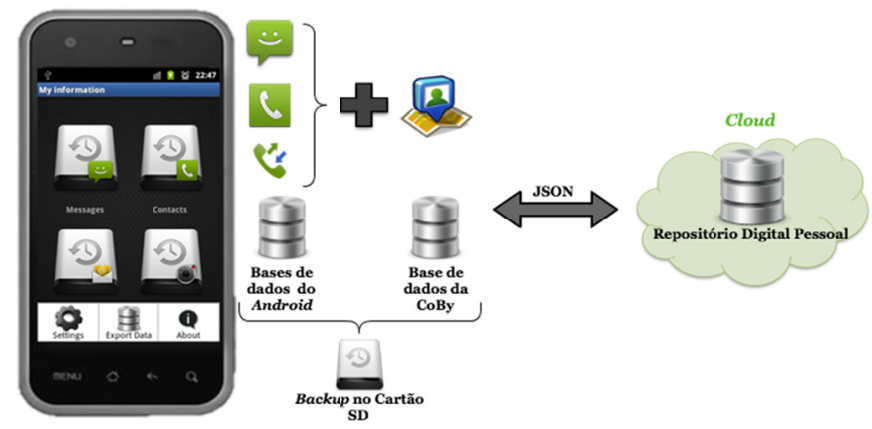

Figura 13 - CoBy (Contextualized Backup and Restore).

Para o sistema operativo Android existem algumas tecnologias que dão suporte à geo- 
localização, sendo designadas por Location Providers (Zhuang, Kim, \& Singh, 2010), (Meier, 2010), (Kumar, Qadeer, \& Gupta, 2009). Nesta aplicação, a localização pode ser obtida usando três formas distintas: GPS (Global Positioning System); Network Location Provider (engloba Cell-ID e $\mathrm{Wi}-\mathrm{Fi}$ ); Triangulação por Cell-ID.

GPS (Kaplan \& Hegarty, 2006), (Djuknic \& Richton, 2001) é um sistema de navegação por satélite que permite fornecer algumas informações a um receptor, nomeadamente a sua posição geográfica. Este representa o método mais preciso de obtenção da localização. Usando Network Location Provider, a localização é obtida, não só, através da informação vinda das estações-base da operadora móvel, mas também dos pontos de acesso $W i-F i$ aos quais o dispositivo se encontra ligado. Este representa o método mais rápido de obter a localização. O Cell-ID (Trevisani \& Vitaletti, 2004) indica a posição da antena à qual o dispositivo se encontra ligado, e trata-se da forma de localização menos precisa.

Um objecto digital por si só já tem agregadas informações de contextualização, como é o caso da data, hora, destinatário, etc. Neste projecto, a contextualização adicional, consiste em associar informação de geo-localização ao objecto digital, no momento em que o utilizador o recebe, envia ou cria. Os parâmetros de informação de geolocalização usados para a contextualização são os seguintes: Latitude; Longitude; GSM Cell-ID; GSM Area Code; Morada. Para a localização do utilizador no momento em que recebeu, enviou ou criou um contacto, SMS ou chamada, é apurado se este possui o GPS activo. No caso afirmativo, é usado este sistema de geo-localização. No caso negativo, é investigado se tem o Network Location Provider activo. Se tiver, usa esse provider para se localizar. Se o GPS e Network Location Provider se encontrarem ambos inactivos é usada a localização por Cell-ID, que se encontra permanentemente activa, e permite saber aproximadamente a localização do utilizador. Se dispuser de todos os providers activos, é dado preferências ao de GPS, seguidamente do Network Location Provider, por questões de precisão. A geo-codificação (obtenção da morada a partir das coordenadas) só é obtida, imediatamente, se o utilizador tiver acesso à Internet (GSM ou Wi-Fi). Caso o utilizador não tenha uma ligação à Internet no momento em que surgiu o objecto digital, é guardado na base de dados da aplicação CoBy apenas as coordenadas (GSM Cell-ID + GSM Area Code e/ou latitude + longitude). A geo-codificação é conseguida posteriormente quando o utilizador já tiver oportunidade de se ligar a uma rede $W i-F i$ ou GSM.

A duração da bateria dos dispositivos móveis é um dos grandes problemas com que os programadores e utilizadores se deparam. É essencial que se desenvolvam aplicações que de alguma forma, consumam menos recursos energéticos possíveis. No que toca à geo-localização é estabelecido um compromisso entre o consumo de bateria e a precisão de localização.

Outro aspecto que implicaria um consumo exaustivo dos recursos energéticos do dispositivo móvel seria a existência de um serviço para detectar a chegada de SMSs ou chamadas. Colmatou-se esse problema usando para isso o conceito de Broadcast Receiver para despoletar o serviço (Shu, Du, \& Chen, 2009), e foi utilizado neste caso, a pensar nesta questão. Este activa o serviço só quando recebe um determinado evento, 
neste caso a recepção de uma SMS ou uma chamada, evitando a necessidade de ter um serviço a correr permanentemente.

A detecção do envio, recepção ou criação de uma SMS, chamada, ou contacto é feito usando abordagens diferentes, tal como é ilustrado na Tabela 2. Sempre que, ao dispositivo móvel chega uma SMS ou uma chamada existe um Broadcast Receiver que detecta a sua chegada, usando o sistema de notificações do Android, e onde é possível aceder ao seu conteúdo. O Broadcast Receiver activa um serviço que irá obter a localização do utilizador usando os sistemas de geo-localização disponíveis no dispositivo móvel, no momento. Quando o utilizador, envia uma SMS, efectua uma chamada ou cria um contacto existe um ContentObserver que detecta esse acto. Assim que este é notado, o serviço responsável pela obtenção da geo-localização é activado e o utilizador é localizado.

Tabela 2 - Abordagem usada para envio/recepção de chamadas e SMSs.

\begin{tabular}{|c|c|}
\hline Eventos & A bordagem usada \\
\hline SM S enviada & Content Observer \\
\hline Chamada efectuada & Broadcast Receiver \\
\hline Chamada recebida & ContentObserver \\
\hline Criação de contacto & Broadcast Receiver \\
\hline
\end{tabular}

Seguidamente é guardado na base de dados da aplicação CoBy toda informação de geolocalização que se conseguir apurar. É criada uma tabela semelhante à ilustrada na Figura 14 por cada grupo de objectos digitais. Na base de dados da aplicação CoBy é unicamente guardada informação relativa à geo-localização. Todo o restante conteúdo da SMS, contacto ou chamada não está presente nesta base de dados, devido ao facto de se encontrarem acessíveis a partir das bases de dados do Android, evitando desta forma redundância de informação. Caso o utilizador apague um dos seus objectos digitais, a informação de geo-localização relativamente a esse objecto é mantida na base de dados da aplicação CoBy, mas com a indicação de que este foi apagado. Desta forma o utilizador sabe que apagou o objecto e tem acesso ao seu contexto, apenas desconhece qual o seu conteúdo. Tem também a possibilidade de não o fazer, e apagar toda a informação relativa ao objecto que previamente apagou na base de dados do Android.

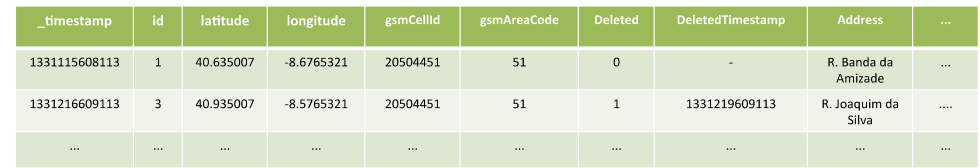

Figura 14 - Tabela da Base de dados da aplicação CoBy.

De forma a persistir os dados localmente no dispositivo móvel, a plataforma Android disponibiliza uma abstracção designada Content Provider (Hashimi, Komatineni, \& MacLean, 2010), acedido através de cursores de uma forma espectável e independentemente da fonte de dados utilizada. Para usar os padrões nativos deste 
sistema operativo, foi utilizada uma base de dados SQLite ${ }^{1}$ para guardar os dados localmente, construindo-se um Content Provider para facilitar o acesso aos mesmos (Owens, 2006). O timestamp que representa a data e o tempo de determinado evento, funciona como chave primária em todas as tabelas da base de dados da aplicação CoBy. Pois, dois objectos terão sempre timestamps diferentes. O ID do objecto só é obtido posteriormente, por pesquisa na base de dados do Android, e por comparação dos timestamps. Desta forma é possível identificar um objecto inequivocamente, nas duas bases de dados.

Na aplicação CoBy o utilizador tem total controlo sobre os seus dados. Existem opções que permitem uma vigilância afincada sobre aquilo que o utilizador pretende ou não enviar para o repositório digital pessoal, assim como aquilo que pretende ou não preservar no cartão SD do dispositivo móvel, como backup. A aplicação CoBy sincroniza-se com o repositório digital pessoal usando para isso um Web-service REST (Cobârzan, 2010), (He, 2003) que consome e produz dados no formato JSON (JavaScript Object Notation) $^{2}$. Na Figura 15 encontra-se representada a estrutura dos objectos JSON comum aos vários tipos de objectos digitais que são enviados para o Web-service. Consoante o tipo de objecto digital, existem alguns campos comuns e outros específicos de cada tipo de dados. A título de exemplo, na Figura 16 está ilustrado o formato completo de um objecto JSON do tipo SMS, constituído pelos seguintes campos:

- Object Type: identificador do objecto (SMS, Contactos, Chamadas, etc.);

- Created Time: identifica a data e hora da criação;

- Address, longitude, latitude, Cell-ID: informação de localização;

- Own Contact: identifica o número do cartão de onde surgiu o objecto;

- Person Contact: representa o número da pessoa com a qual se está a estabelecer contacto.

- Source: indica se a mensagem foi recebida ou enviada;

- Body: representa o corpo da SMS propriamente dito;

\begin{tabular}{|c|c|c|c|c|c|c|c|}
\hline $\begin{array}{c}\text { Object } \\
\text { Type }\end{array}$ & $\begin{array}{c}\text { Created } \\
\text { Time }\end{array}$ & Address & Latitude & Longitude & Cell-ID & $\begin{array}{c}\text { Own } \\
\text { Contact }\end{array}$ & $\ldots$ \\
\hline
\end{tabular}

Figura 15 - Estrutura JSON comum a todos os objectos digitais.

\footnotetext{
${ }^{1}$ http://www.sqlite.org/

2 http://www.json.org/
} 
Caso o utilizado achar que não precisa de preservar os seus objectos no repositório digital pessoal, pode simplesmente usar esta aplicação para fazer backup e restore a partir do cartão SD do seu dispositivo móvel. Mas se houver uma perda ou furto do mesmo, toda a informação perder-se-á.

\begin{tabular}{|c|c|c|c|c|c|c|c|c|c|}
\hline $\begin{array}{c}\text { Object } \\
\text { Type }\end{array}$ & $\begin{array}{c}\text { Created } \\
\text { Date }\end{array}$ & Address & Latitude & Longitude & Cell-ID & $\begin{array}{c}\text { Own } \\
\text { Contact }\end{array}$ & $\begin{array}{c}\text { Person } \\
\text { Contact }\end{array}$ & Source & Body \\
\hline
\end{tabular}

Figura 16 - Estrutura JSON para objectos digitais do tipo SMS.

A utilização de um repositório digital pessoal como plataforma de armazenamento remoto é um dos traços distintivos da aplicação CoBy. Um repositório digital pessoal, mais do que uma plataforma intermédia onde os objectos digitais ficam armazenados à espera de serem restaurados para um dispositivo móvel é uma plataforma que permite organizar e relacionar diferentes tipos de objectos digitais provenientes de várias plataformas e aplicações (Sousa, Pereira, \& Martins, 2012). O repositório digital pessoal é responsável por interpretar as estruturas JSON utilizadas pela aplicação CoBy de forma a criar uma representação semântica dos objectos digitais recebidos, e de forma inversa é responsável por recriar as estruturas JSON a partir da representação semântica do objecto digital quando comunica com a aplicação CoBy. A representação semântica de um objecto digital é armazenada numa embedded triple-store (baseada na base de dados Neo4J ${ }^{3}$ ), e é determinada por uma ontologia (que se encontra em desenvolvimento de forma a ser capaz de lidar com tipos adicionais de objectos digitais). A ontologia que está a ser desenvolvida é fortemente influenciada pela ontologia CIDOC CRM (Group, 2011) com extensões para descrever eventos associados ao ciclo de vida dos objectos digitais, ao próprio repositório digital pessoal, e para descrever os vários tipos de objectos digitais que um utilizador pode armazenar no repositório digital pessoal. O uso desta ontologia permite classificar de forma consistente os objectos digitais, estabelecer as suas propriedades, e descobrir relações entre diferentes objectos digitais, tornado assim possível que o utilizador do repositório digital pessoal tenha a noção da forma como, por exemplo, uma determinada SMS se encaixa com outras formas de conversação digital (mensagens instantâneas, emails, etc.) mantidas com um contacto. Nem todos os objectos digitais podem ser armazenados de forma eficiente somente com recurso à sua descrição semântica. Objectos digitais com conteúdos binários, como por exemplo imagens ou músicas, são armazenados no seu formato binário nativo, tendo a sua representação semântica uma propriedade (URL para a representação nativa) que permite o acesso ao objecto digital no formato original.

As capacidades de classificação e organização de objectos digitais individuais distinguem um repositório digital pessoal das soluções de backup e restore com funcionalidades de armazenamento na Cloud, que normalmente criam arquivos com conjuntos de objectos digitais que têm de ser restaurados para um dispositivo compatível de forma a ficarem novamente acessíveis ao utilizador.

3 http://neo4j.org/ 


\section{Análise da Aplicação}

Subsistem muitas aplicações para Android que, tal como a aplicação CoBy, englobam funcionalidades de backup e restore de SMSs, contactos e histórico de chamadas. Na Tabela 3 encontra-se ilustrada a comparação entre a aplicação CoBy e as aplicações mais usadas no Google Play, e que de alguma forma dispõe de funcionalidades comuns. Será apenas sobre estas que será efectuado algum juízo de valor nesta secção.

Tabela 3 - Comparação entre a aplicação CoBy e as aplicações de backup e restore mais usadas no Google Play ( * Apenas para e-mail).

\begin{tabular}{|c|c|c|c|c|c|c|c|c|c|c|c|c|}
\hline $\begin{array}{c}\text { Algumas } \\
\text { funcionalidades }\end{array}$ & COBy & $\begin{array}{c}\text { SMS } \\
\text { Backup \& } \\
\text { Restore } \\
\text { [RITESH } \\
\text { SAHU] }\end{array}$ & $\begin{array}{c}\text { SMS } \\
\text { Backup } \\
+\end{array} \mid$ & $\begin{array}{c}\text { SMS } \\
\text { Backup \& } \\
\text { Restore } \\
\text { [INFOLIFE } \\
\text { LLC] }\end{array}$ & \begin{tabular}{|c|} 
Call logs \\
Backup \\
$\&$ \\
Restore
\end{tabular} & $\begin{array}{c}\text { JS } \\
\text { Backup }\end{array}$ & $\begin{array}{l}\text { Backup } \\
\text { Contacts }\end{array}$ & $\begin{array}{c}\text { Mobile } \\
\text { backup } \\
\text { II }\end{array}$ & $\begin{array}{c}\text { Super } \\
\text { Backup : } \\
\text { SM S \& } \\
\text { Contactos }\end{array}$ & $\begin{array}{l}\text { Backup } \\
\text { Master }\end{array}$ & $\begin{array}{c}\text { MyBackup } \\
\text { Pro }\end{array} \mid$ & $\begin{array}{c}\text { SMS } \\
\text { BACKUP } \\
n 2 \text { manager }\end{array}$ \\
\hline \multicolumn{13}{|l|}{ SMS } \\
\hline \multicolumn{13}{|l|}{ Contactos } \\
\hline \multicolumn{13}{|l|}{$\begin{array}{l}\text { Histórico de } \\
\text { Chamadas }\end{array}$} \\
\hline \multicolumn{13}{|l|}{$\begin{array}{l}\text { Backup para } \\
\text { SDCard }\end{array}$} \\
\hline \multicolumn{13}{|l|}{ Restore do SDCard } \\
\hline $\begin{array}{c}\text { Backup para } \\
\text { repositório digital } \\
\text { pessoal ou Cloud }\end{array}$ & & * & * & & & & & & * & & & \\
\hline $\begin{array}{c}\text { Restore da } \\
\text { repositório digital } \\
\text { pessoal ou Cloud }\end{array}$ & & * & * & & & & & & * & & & \\
\hline \multicolumn{13}{|l|}{$\begin{array}{c}\text { Backups } \\
\text { automáticos }\end{array}$} \\
\hline \multicolumn{13}{|l|}{$\begin{array}{l}\text { Capacidade de } \\
\text { filtrar informação } \\
\text { que pretende } \\
\text { preservar }\end{array}$} \\
\hline \multicolumn{13}{|l|}{$\begin{array}{c}\text { Suporte repositório } \\
\text { digital pessoal }\end{array}$} \\
\hline Geo-localização & & & & & & & & & & & & \\
\hline
\end{tabular}

A existência de aplicações que possibilitem backup e restore para e ou a partir do cartão de memória do dispositivo móvel já é uma realidade bastante clara, e é uma característica comum a todas as aplicações retratadas na Tabela 3, com a excepção das aplicações SMS Backup+ e Backup Contacts. Os backups podem ser efectuados manualmente ou automaticamente. No caso em que esta tarefa é feita manualmente, pode existir alguma perda de informação. É bastante ineficaz para o utilizador ter de desencadear um backup sempre que recebe ou cria um objecto, ou quando achar que é necessário. Acabando por fazê-lo, mas com intervalos temporais muito espaçados, correndo o risco de perder informação nesse período de tempo. Os backups automáticos são bastante mais eficazes, libertando o utilizador da preocupação de salvaguardar os seus dados periodicamente, tendo neste caso, a possibilidade de definir na aplicação quando e de quanto em quanto tempo o pretende fazer. Esta funcionalidade está presente não só na aplicação CoBy, como também em todas as restante, com a excepção das aplicações Backup Contacts, Mobile Backup II e Super Backup: SMS \& Contacts.

Tudo aquilo que é guardado com o objectivo de ser preservado deve sofrer um controlo integral por parte do utilizador. Existem sempre objectos digitais em que a sua preservação pode não ser desejada. A aplicação CoBy fornece ao utilizador este 
controlo bastante pormenorizado, permitindo-lhe preservar unicamente aquilo que pretender. Trata-se de uma funcionalidade única da aplicação CoBy.

Já existem aplicações que de alguma forma permitem o armazenamento e a preservação de dados na Cloud. Algumas delas só disponibilizam essa funcionalidade para o e-mail. Três bons exemplos disso são as aplicações SMS Backup \& Restore desenvolvido por RITESH SAHU, Super Backup e SMS Backup + que permitem a exportação dos dados para uma conta de e-mail. Tornando-se confuso e pouco objectivo para o utilizador. As aplicações CoBy, JS Backup, Backup Contacts e MyBackup Pro são bastante mais inovadoras neste aspecto, pois permitem a ligação a um repositório digital pessoal onde a informação se encontra organizada, estruturada e privada. Os repositórios usados por estas aplicações são: DropBox, SugarSync ou Google Docs.

Nenhuma das aplicações ilustrada na Tabela 3 permite qualquer tipo de geocontextualização de informação. Trata-se de uma funcionalidade única da aplicação CoBy, permitindo ao utilizador preservar não só o conteúdo mas também o local em que os objectos digitais surgiram.

A aplicação CoBy consegue englobar funcionalidades como: recolha, preservação e contextualização de vários tipos de objectos digitais (SMSs, contactos, histórico de chamadas); geo-localização dos objectos; armazenamento da informação em locais distintos (cartão SD e repositório pessoal); sincronismo dos dados com o repositório; backups automáticos e restore para/do cartão SD e repositório pessoal; preservar apenas objectos digitais do interesse do utilizador; interface gráfica de acesso aos dados no dispositivo móvel e no repositório. Nenhuma das restantes conseguem integrar na sua totalidade as funcionalidades presentes na aplicação CoBy. Mas aquilo que de facto, se pode considerar inovador, é a geo-contextualização dos objectos, possibilitando ao utilizador legitimar o surgimento dos mesmos, bem como a possibilidade de garantir a sua preservação num repositório digital pessoal.

\section{Conclusões}

Neste artigo apresentou-se a aplicação CoBy como protótipo de um modelo de recolha, preservação e contextualização de informação. Esta aplicação demonstra uma elevada utilidade para utilizadores de dispositivos móveis. Trata-se de uma aplicação com capacidade de backup automático e restore de SMSs, contactos e histórico de chamadas, devidamente contextualizados. O utilizador pode fazer uma cópia de segurança e restauro não só para o seu repositório digital com também para cartão de memória do seu dispositivo. A sua ligação a um repositório digital pessoal permite colmatar o problema da acelerada obsolescência inerente às diversas tecnologias e softwares que vão surgindo. Assim, vê-se garantida a preservação persistente e continuada do material digital, sem receio de perda, detioração ou corrupção dos mesmos. A contextualização permite ao utilizador a criação de uma imagem mental inteligível de tudo aquilo que o rodeava quando recebeu, criou ou enviou o objecto digital. Permitindo, desta forma não só preservar o conteúdo propriamente dito, mas também a imagem mental circundante. Com esta aplicação, o utilizador consegue salvaguardar as SMSs, contactos e/ou chamadas que achar que tem relevância para tal 
e dar um grande contributo para a escrita da sua própria história, não só pessoal mas também profissional.

Com um método semelhante ao descrito para as SMSs, contactos e chamadas, a aplicação CoBy irá permitir não só a recolha, preservação e contextualização destes objectos, mas também de imagens, emails, fotos, bookmarks, músicas, calendário, etc. Em suma, todo o material digital disponível no dispositivo móvel e que seja do interesse do utilizador preservar. Serão também efectuados testes de usabilidade de forma a tornar a aplicação mais robusta. Futuramente, a aplicação CoBy será extensível a outros sistemas operativos móveis.

Agradecimentos: Este trabalho foi financiado em parte pela bolsa SFRH/BD/62554/2009 da Fundação Portuguesa para a Ciência e Tecnologia.

\section{Referências}

Abowd, G. D., Ebling, M., Hung, G., Lei, H., \& Gellersen, H. W. (2002). Context-aware computing. Pervasive Computing, IEEE, 99(3), 22-23.

Arellano, M. A. (2004). Preservation of digital documents. Ciência da Informação, $33(2), 15^{-27 .}$

BOOK, B. (2002). Reference Model for an Open Archival Information System (OAIS).

Cobârzan, A. (2010). Consuming Web Services on Mobile Platforms. Informatica Economica, 14(3), 1453-1305.

da Costa, R. (2007). História e Memória: a importância da preservação e da recordação do passado. SINAIS - Revista Eletrônica - Ciências Sociais, 1, 02-15.

Darwin, I. F. (2012). Android Cookbook (First Edition ed.): O'Reilly Media.

Dey, A. K. (2001). Understanding and using context. Personal and ubiquitous computing, 5(1), 4-7.

Djuknic, G. M., \& Richton, R. E. (2001). Geolocation and assisted GPS. Computer, 34(2), 123-125.

Gartner. (2012). Worldwide Mobile Device Sales to End Users Retrieved 05-06-2012, from http://www.gartner.com/technology/home.jsp

Group, C. C. S. I. (2011). The CIDOC Conceptual Reference Model Retrieved o5-062012, from http://www.cidoc-crm.org/

Hashimi, S. Y., Komatineni, S., \& MacLean, D. (2010). Pro Android 2: Springer.

He, H. (2003). What is service-oriented architecture. Publicação eletrônica 30.

Heery, R., \& Anderson, S. (2005). Digital repositories review. Joint Information Systems Committee.

Kaplan, E. D., \& Hegarty, C. J. (2006). Understanding GPS principles and applications. Norwood: Artech House Publishers. 
Kumar, S., Qadeer, M. A., \& Gupta, A. (2009). Location based services using android (LBSOID). Paper presented at the Internet Multimedia Services Architecture and Applications (IMSAA), 2009 IEEE International Conference, Bangalore.

Mehra, P. (2012). Context-Aware Computing: Beyond Search and Location-Based Services. Internet Computing, IEEE, 16(2), 12-16.

Meier, R. (2010). Professional Android 2 application development. USA: Wiley Publishing, Inc.

Ottaviani, V., Lentini, A., Grillo, A., Di Cesare, S., \& Italiano, G. F. (2011). Shared Backup \& Restore: Save, Recover and Share Personal Information into Closed Groups of Smartphones. Paper presented at the New Technologies, Mobility and Security (NTMS), 2011 4th IFIP International Conference.

Owens, M. (2006). The definitive guide to SQLite: Apress.

Pascoe, J. (1998). Adding generic contextual capabilities to wearable computers. Paper presented at the Wearable Computers, 1998. Digest of Papers. Second International Symposium.

Saidis, K., \& Delis, A. (2007). Type-consistent digital objects. D-Lib Magazine, 13(5), 4.

Shu, X., Du, Z., \& Chen, R. (2009). Research on mobile location service design based on Android. Paper presented at the Proceedings - 5th Int. Conf, WiCOM 2009.

Sousa, J., Pereira, M., \& Martins, J. A. (2012). Improving Browser History Using Semantic Information. ICEIS 2012 - 14th International Conference on Enterprise Information Systems.

Trevisani, E., \& Vitaletti, A. (2004). Cell-ID location technique, limits and benefits: an experimental study. Paper presented at the Mobile Computing Systems and Applications.

Zhuang, Z., Kim, K. H., \& Singh, J. P. (2010). Improving energy efficiency of location sensing on smartphones. Paper presented at the Proceedings of the 8th international conference on Mobile systems, applications, and services (MobiSys '10), ACM, New York, NY, USA. 